\title{
Caracterização espectral multitemporal dos cereais de estação fria em imagens de satélite com média resolução espacial
}

\author{
Multitemporal spectral characterization of cool season cereals in satellite images with \\ moderate spatial resolution
}

\author{
Eliana Lima da Fonseca ${ }^{\mathrm{I}}$ Jose Rodrigo Fernandez Caresani ${ }^{\mathrm{II}}$ Alexandre Costa Varella ${ }^{\mathrm{II}}$
}

\section{RESUMO}

A fim de avaliar os padrões de resposta de áreas cultivadas com cereais de estação fria destinados para pastagens e para produção de grãos em imagens de satélite, foram analisados perfis temporais de indice de vegetação por diferença normalizada (NDVI), adquiridos em 29 áreas cultivadas com trigo e azevém anual, nos Estados do Rio Grande do Sul e Paraná. Para cada área foi informada a espécie cultivada (trigo ou azevém anual) e a coordenada do ponto central da área adquirido por meio do Global Positioning System (GPS). Foram usadas as imagens do sensor MODIS (Moderate Resolution Imaging Spectroradiometer), com resolução espacial de 250 metros, sobre cada área monitorada, de onde os valores de NDVI foram extraídos. Os perfis temporais de NDVI mostraram que os cultivos de produção de grãos têm um comportamento espectral típico de cultivos agrícolas, enquanto que, nas áreas cultivadas para a produção de pastagem, não foi observado esse mesmo padrão. As diferenças nos padrões temporais observadas se devem a modificações que o pastoreio impõe na fenologia e na morfologia dessas plantas.

Palavras-chave: moderate resolution imaging spectroradiometer (MODIS), índice de vegetação por diferença normalizada (NDVI), gramíneas, morfologia, fenologia.

\section{ABSTRACT}

In order to evaluate the satellite image patterns between such cool season cereals cultivated areas intended for grazing or grain production, Normalized Difference

\begin{abstract}
Vegetation Index (NDVI) temporal profiles were analyzed. This data was acquired from twenty nine wheat and annual ryegrass cultivated areas in the states of Rio Grande do Sul and Paraná. For each area, the cultivated species (wheat or ryegrass), as well as the respective central point coordinates, acquired via Global Positioning System (GPS) was informed. NDVI values were extracted over each monitored area from MODIS (Moderate Resolution Imaging Spectroradiometer) sensor images, with spatial resolution of 250 meters. The NDVI temporal profiles showed that grain production areas have a typical agricultural field spectral pattern. The same pattern was not observed for the grazing pasture areas. The differences observed in these temporal patterns are defined by the changes that grazing has imposed on the phenology and morphology of these plants.
\end{abstract}

Key words: moderate resolution imaging spectroradiometer (MODIS), normalized difference vegetation index (NDVI), graminae, morphology, phenology.

\section{INTRODUÇÃO}

Os principais cereais de estação fria cultivados para a produção de grãos no Brasil são o trigo, a aveia branca, o centeio, a cevada e o triticale. Para a produção de pastagens são utilizados principalmente $\mathrm{o}$ azevém anual e a aveia preta. Essas plantas possuem em comum a família botânica (gramíneas) e as exigências térmicas para o seu cultivo

'Departamento de Geografia, Instituto de Geociências, Universidade Federal do Rio Grande do Sul (UFRGS), 91501-970, Porto Alegre, RS, Brasil. E-mail: eliana.fonseca@ufrgs.br. Autor para correspondência.

IPrograma de Pós-graduação em Sensoriamento Remoto, Centro Estadual de Pesquisas em Sensoriamento Remoto e Meteorologia, Universidade Federal do Rio Grande do Sul (UFRGS), Porto Alegre, RS, Brasil.

"IIEmbrapa Pecuária Sul, Bagé, RS, Brasil. 
(baixas temperaturas). A identificação da espécie cultivada em um talhão agrícola utilizando técnicas de sensoriamento remoto orbital parte da premissa de que essa espécie pode ser caracterizada a partir de seu padrão de resposta espectral em imagens multiespectrais (LILLESAND et al., 2004). Essa análise fica prejudicada em uma única data de imageamento, já que várias culturas apresentam padrões de resposta espectral semelhantes e também porque nem todos os talhões de cultivo são semeados em uma mesma data; assim, uma mesma cultura pode estar em estádios fenológicos distintos na data do imageamento (PAXLENNEY \& WOODCOCK, 1997). Por essa razão, uma abordagem, em estudos de mapeamento e monitoramento de áreas agrícolas, é a análise multitemporal de imagens de satélite. Para análises dessa natureza, o ideal é que sejam disponibilizadas imagens adquiridas durante todo o ciclo de cultivo, que permitam identificar as variações na resposta espectral causadas pelas diferentes fases do ciclo fenológico (CAMPBELL, 2006). O sensor orbital EOSMODIS, a bordo dos satélites Terra e Acqua, possui uma resolução espacial de 250 metros nas regiões do vermelho e infravermelho próximo do espectro eletromagnético e uma resolução temporal de dois dias, sendo adequado para o monitoramento multitemporal de áreas cultivadas (DORAISWAMY et al., 2004).

O Índice de Vegetação por Diferença Normalizada (NDVI) é calculado a partir de valores de reflectância nas regiões do vermelho e infravermelho próximo do espectro eletromagnético $\left(\mathrm{NDVI}=\left(\rho_{\mathrm{IVP}}-\right.\right.$ $\left.\rho_{\mathrm{V}}\right) /\left(\rho_{\mathrm{IVP}}+\rho_{\mathrm{V}}\right)$, sendo $\rho_{\mathrm{IVP}}=$ reflectância no infravermelho próximo e $\rho_{\mathrm{v}}=$ reflectância no vermelho). Esse índice é adimensional e varia entre -1 e 1 . O contraste da resposta da vegetação nesses comprimentos de onda faz com que a vegetação seja realçada em relação aos demais alvos, o que facilita a sua identificação e o seu monitoramento a partir de dados de sensoriamento remoto (ASRAR et al., 1984).

O presente trabalho tem por objetivo analisar a caracterização espectral multitemporal de áreas cultivadas com cereais de estação fria para a produção de pastagens e produção de grãos, utilizando imagens de NDVI do sensor MODIS, a fim de identificar os padrões de resposta e suas variações frente às variações do ciclo fenológico. Esse tipo de análise das variações do ciclo fenológico a partir da caracterização espectral multitemporal já vem sendo feita por vários autores nos últimos anos, mas a maioria dos trabalhos utiliza uma única espécie, visando a identificação de eventos fenológicos (FISHER et al., 2006), a estimativa da duração do período de cultivo (XIN, et al., 2002) e o monitoramento das condições de crescimento da cultura (UNGANAI \& KOGAN, 1998).

O presente artigo contribui com a análise da caracterização espectral multitemporal do trigo e do avezém anual, os quais apresentam morfologias semelhantes, mas ciclos fenológicos distintos, em função do uso (produção de grãos e produção de pastagens). De forma individual, o entendimento dos padrões da variação espectral multitemporal de cada uma das espécies monitoradas neste trabalho permitirá monitorar as condições de crescimento dos cultivos, visando a sua utilização em modelos de estimativa de produtividade vegetal, quando a avaliação dos padrões observados for feita em associação com os dados de clima e produtividade. $\mathrm{O}$ entendimento desses padrões também permitirá a definição dos melhores períodos do ciclo de cultivo para a separação dessas espécies em procedimentos de classificação automática de imagens e obtenção de mapeamentos atualizados e acurados das áreas cultivadas com pastagens de estação fria na região sul do Brasil, os quais são inexistentes.

\section{MATERIAL E MÉTODOS}

O período de estudo foi compreendido entre os meses de março e novembro dos anos de 2005 e 2007 e foi definido de acordo com a época de cultivo dos cereais de estação fria na região Sul do Brasil. Foram monitoradas 20 áreas de cultivo de trigo localizadas no Estado do Rio Grande do Sul e nove áreas de cultivo de azevém anual nos Estados do Rio Grande do Sul e Paraná.

Foram utilizadas imagens do sensor EOSMODIS, distribuídas por meio do produto "MOD13", o qual contém as composições de NDVI que foram analisadas. A composição é formada pelo NDVI máximo medido em 16 dias para cada pixel, em cada uma das datas de aquisição das imagens, o que permite a obtenção de um produto livre da influência das nuvens. Foram utilizados os arquivos de imagens posicionados nas células H13V11 e H13V12, que cobrem completamente a área dos Estados do Rio Grande do Sul e do Paraná. As imagens foram processadas no aplicativo Modis Reprojections Tools, disponibilizado pela NASA exclusivamente para imagens desse sensor, onde os arquivos das duas células, adquiridos em cada uma das datas analisadas, foram combinados para formar uma imagem única. Nesse programa também foi feita a reprojeção das imagens, mediante a conversão da projeção sinusoidal, na qual são fornecidas as imagens para projeção cilíndrica equidistante para a 
integração destas no banco de dados georreferenciados.

Foi montado um banco de dados georreferenciados, utilizando o aplicativo de sistemas de informações geográficas Spring, no qual foram inseridas as imagens de NDVI e as coordenadas das áreas de cultivos monitoradas. As imagens foram identificadas por ano e pelo dia Juliano referente ao primeiro dia de cada composição de 16 dias utilizado para montar a composição de máximo NDVI.

As coordenadas geodésicas centrais de cada talhão de cultivo monitorado foram obtidas com a utilização de um receptor de GPS (Tabela 1). Foram monitorados talhões com tamanho variável, mas a unidade de monitoramento foi o pixel central de cada uma das 29 áreas. Estes foram isolados e vetorizados nas imagens utilizadas, visando dessa forma evitar a contaminação dos valores de reflectância das áreas monitoradas pela reflectância da vegetação das áreas do entorno.

Para as áreas de azevém anual foram analisadas imagens adquiridas no ano de 2007, uma vez que as coordenadas das áreas de cultivo foram adquiridas em campo durante esse ano. Para as áreas de trigo foram analisadas as imagens adquiridas em 2005, devido à disponibilidade de dados de campo referentes ao posicionamento das lavouras adquiridos nesse ano. Os diferentes anos de aquisição das imagens não são um empecilho para a comparação dos dados, uma vez que as imagens do sensor MODIS já são fornecidas pela NASA com calibração radiométrica e correção atmosférica, todas geradas com o mesmo algoritmo de calibração (XIONG \& BARNES,
2006), e a variável utilizada (NDVI) permite a comparação dos seus valores, tanto no tempo, como no espaço (JACKSON \& HUETE, 1991).

Utilizando o módulo "extração de estatísticas de imagem", disponível no aplicativo Spring, foram coletados os valores de NDVI para todas as datas analisadas sobre todos os pixels isolados de cada uma das áreas monitoradas. Esses valores foram dispostos em gráficos, tendo as datas das imagens no eixo horizontal e os valores do NDVI no eixo vertical. Foram gerados quatro gráficos, sendo um para as áreas cultivadas com azevém anual, dois para as áreas cultivadas com trigo (em função dos diferentes padrões de resposta observados) e um com os valores médios das respostas espectrais apresentadas nos gráficos anteriores. As variações multitemporais da resposta espectral foram comparadas com as variações do ciclo fenológico do azevém anual e do trigo.

\section{RESULTADOS E DISCUSSÃO}

No ciclo fenológico dos cereais de estação fria cultivados para a produção de grãos, são identificadas as seguintes etapas: emergência, afilhamento, alongamento, florescimento, formação de grãos, maturação e senescência (Figura 1A). Em função do calendário de cultivo para esses cereais ser definido regionalmente e considerar na sua elaboração tanto as exigências climáticas, quanto os períodos de risco da cultura, as diferentes fases fenológicas em diferentes áreas de cultivo ocorrem de forma quase simultânea em uma mesma região. Na análise dos

Tabela 1 - Coordenadas geodésicas latitude e longitude do centro das áreas monitoradas e identificação da espécie cultivada.

\begin{tabular}{|c|c|c|c|}
\hline Coordenadas geodésicas (latitude e longitude) & Espécie & Coordenadas geodésicas (latitude e longitude) & Espécie \\
\hline$-31^{\circ} 04^{\prime} 16^{\prime \prime},-54^{\circ} 45^{\prime} 17^{\prime \prime}$ & Azevém & $-28^{\circ} 29^{\prime} 30^{\prime \prime},-52^{\circ} 17^{\prime} 51^{\prime \prime}$ & Trigo \\
\hline$-31^{\circ} 04^{\prime} 18^{\prime \prime},-54^{\circ} 45^{\prime} 31^{\prime \prime}$ & Azevém & $-28^{\circ} 27^{\prime} 50^{\prime \prime},-52^{\circ} 20^{\prime} 12^{\prime \prime}$ & Trigo \\
\hline$-31^{\circ} 04^{\prime} 14^{\prime \prime},-54^{\circ} 45^{\prime} 30^{\prime \prime}$ & Azevém & $-28^{\circ} 16^{\prime} 47^{\prime \prime},-52^{\circ} 14^{\prime} 41^{\prime \prime}$ & Trigo \\
\hline$-31^{\circ} 04^{\prime} 16^{\prime \prime},-54^{\circ} 45^{\prime} 13^{\prime \prime}$ & Azevém & $-28^{\circ} 27^{\prime} 50^{\prime \prime},-52^{\circ} 23^{\prime} 06^{\prime \prime}$ & Trigo \\
\hline$-31^{\circ} 04^{\prime} 12^{\prime \prime},-54^{\circ} 44^{\prime} 55^{\prime \prime}$ & Azevém & $-28^{\circ} 24^{\prime} 48^{\prime \prime},-52^{\circ} 26^{\prime} 58^{\prime \prime}$ & Trigo \\
\hline$-31^{\circ} 04^{\prime} 52^{\prime \prime},-54^{\circ} 44^{\prime} 50^{\prime \prime}$ & Azevém & $-28^{\circ} 23^{\prime} 17^{\prime \prime},-52^{\circ} 27^{\prime} 48^{\prime \prime}$ & Trigo \\
\hline$-31^{\circ} 21^{\prime} 00^{\prime \prime},-54^{\circ} 15^{\prime} 16^{\prime \prime}$ & Azevém & $-28^{\circ} 22^{\prime} 10^{\prime \prime},-52^{\circ} 28^{\prime} 37^{\prime \prime}$ & Trigo \\
\hline$-25^{\circ} 07^{\prime} 00^{\prime \prime},-52^{\circ} 41^{\prime} 00^{\prime \prime}$ & Azevém & $-28^{\circ} 23^{\prime} 34^{\prime \prime},-52^{\circ} 29^{\prime} 10^{\prime \prime}$ & Trigo \\
\hline$-25^{\circ} 24^{\prime} 18^{\prime},-52^{\circ} 28^{\prime} 29^{\prime \prime}$ & Azevém & $-28^{\circ} 26^{\prime} 52^{\prime \prime},-52^{\circ} 30^{\prime} 16^{\prime \prime}$ & Trigo \\
\hline$-28^{\circ} 48^{\prime} 00^{\prime \prime},-52^{\circ} 58^{\prime} 55^{\prime \prime}$ & Trigo & $-28^{\circ} 14^{\prime} 10^{\prime \prime},-52^{\circ} 36^{\prime} 06^{\prime \prime}$ & Trigo \\
\hline$-28^{\circ} 42^{\prime} 36^{\prime \prime},-52^{\circ} 02^{\prime} 02^{\prime \prime}$ & Trigo & $-28^{\circ} 12^{\prime} 07^{\prime \prime},-52^{\circ} 33^{\prime} 03^{\prime \prime}$ & Trigo \\
\hline$-28^{\circ} 33^{\prime} 37^{\prime \prime}-52^{\circ} 16^{\prime} 38^{\prime \prime}$ & Trigo & $-28^{\circ} 09^{\prime} 46^{\prime \prime},-52^{\circ} 36^{\prime} 54^{\prime \prime}$ & Trigo \\
\hline$-28^{\circ} 31^{\prime} 17^{\prime \prime},-52^{\circ} 17^{\prime} 27^{\prime \prime}$ & Trigo & $-28^{\circ} 10^{\prime} 02^{\prime \prime},-52^{\circ} 38^{\prime} 50^{\prime \prime}$ & Trigo \\
\hline$-28^{\circ} 31^{\prime} 08^{\prime \prime},-52^{\circ} 19^{\prime} 14^{\prime \prime}$ & Trigo & $-28^{\circ} 12^{\prime} 15^{\prime \prime},-52^{\circ} 40^{\prime} 46^{\prime \prime}$ & Trigo \\
\hline$-28^{\circ} 30^{\prime} 28^{\prime \prime},-52^{\circ} 18^{\prime} 41^{\prime \prime}$ & Trigo & & \\
\hline
\end{tabular}

Nota: parâmetros geodésicos das coordenadas: datum WGS84, projeção cilíndrica equidistante.

Ciência Rural, v.40, n.10, out, 2010. 
valores espectrais foi constatada a existência de dois padrões multitemporais de NDVI distintos. O padrão espectral multitemporal apresentado na figura $2 \mathrm{~A}$ é relativo às cultivares de ciclo médio, semeadas no início da estação de plantio, sendo denominado padrão 1 neste trabalho. Já o padrão espectral multitemporal apresentado na figura $2 \mathrm{~B}$ é relativo às cultivares de ciclo precoce, semeadas no final da época recomendada para o plantio, denominado padrão 2 . Os valores de NDVI, em todas as áreas de trigo, independentemente da época de semeadura, apresentam as seguintes características: a) baixos valores associados ao período de germinação e início do crescimento; b) aumento linear associado ao crescimento vegetativo; c) estabilização nos valores associados à emissão das inflorescências e formação de grãos, quando não há mais incrementos no Índice de Área Foliar (IAF); d) redução dos valores associados ao período de enchimento de grãos e senescência.

No padrão 1 (Figura 2A) as fases iniciais do ciclo fenológico em todas as diferentes áreas analisadas podem ser identificadas pelo valor baixo de NDVI do dia 97 (primeira quinzena de abril) e pelo ciclo que finaliza entre os dias 241 e 289 (final de agosto e primeira quinzena de outubro). No padrão 2 (Figura 2B) o início do cicloé identificado no dia 193 (segunda quinzena de julho) e finalizado no dia 305 (primeira quinzena de novembro), caracterizado pelo plantio de variedades de ciclo curto. Foram observadas

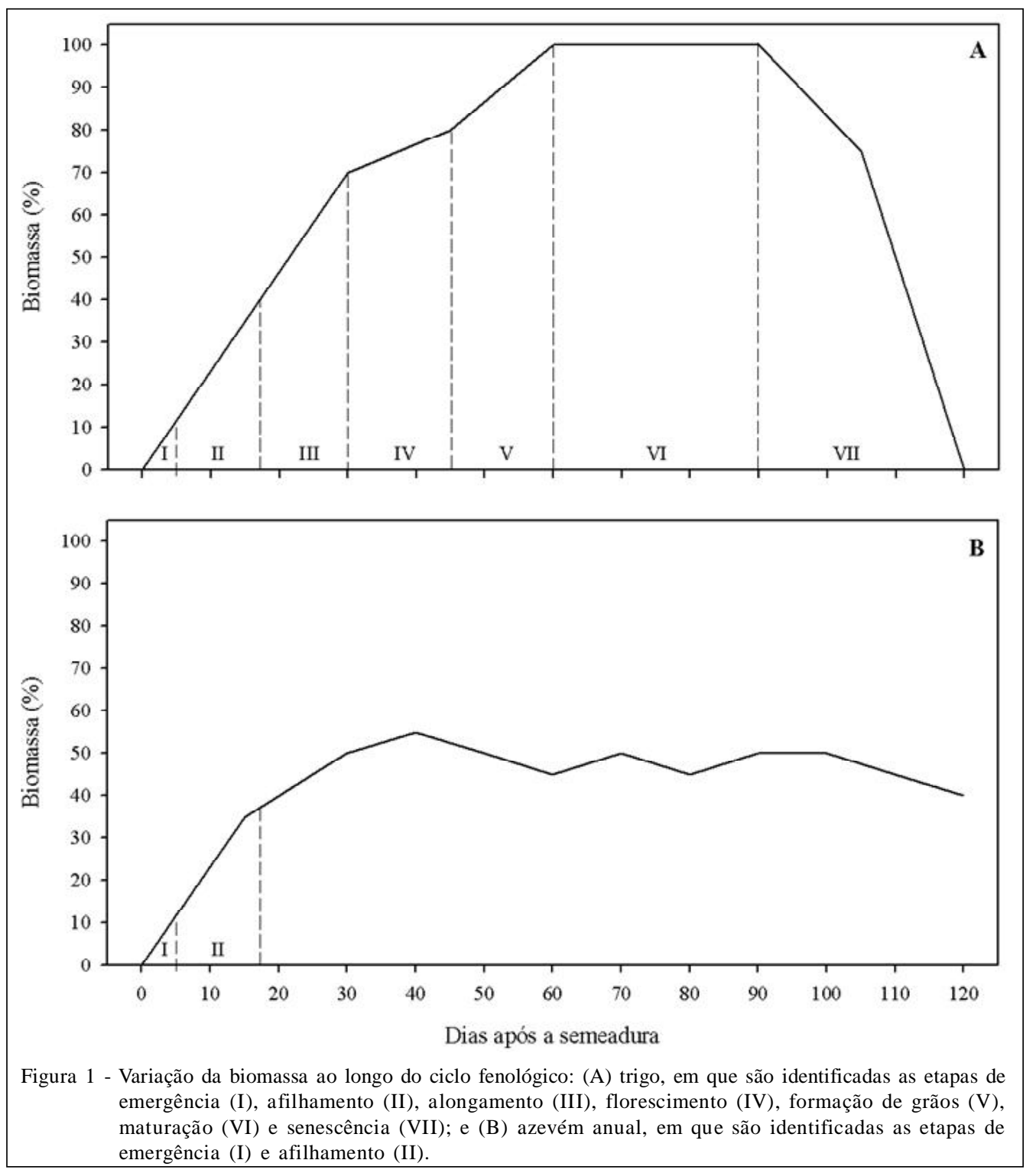

Ciência Rural, v.40, n.10, out, 2010. 
diferenças entre os dois padrões temporais de valores de NDVI que são função da duração e da uniformidade do ciclo de cultivo do trigo. No padrão 1 o ciclo de cultivo se estende por um período maior do que o padrão 2. Já no padrão 2 o ciclo todo é mais uniforme, em função do término do período favorável ao cultivo dos cereais de estação fria no final do inverno, na região sul do Brasil. Nas figuras 2A e 2B observa-se que, em ambos padrões multitemporais de trigo, as variações da resposta espectral correspondem às variações da fenologia das áreas de cultivo, sendo esse padrão de variação temporal do NDVI característico de um cultivo agrícola (JACKSON et al., 1983).
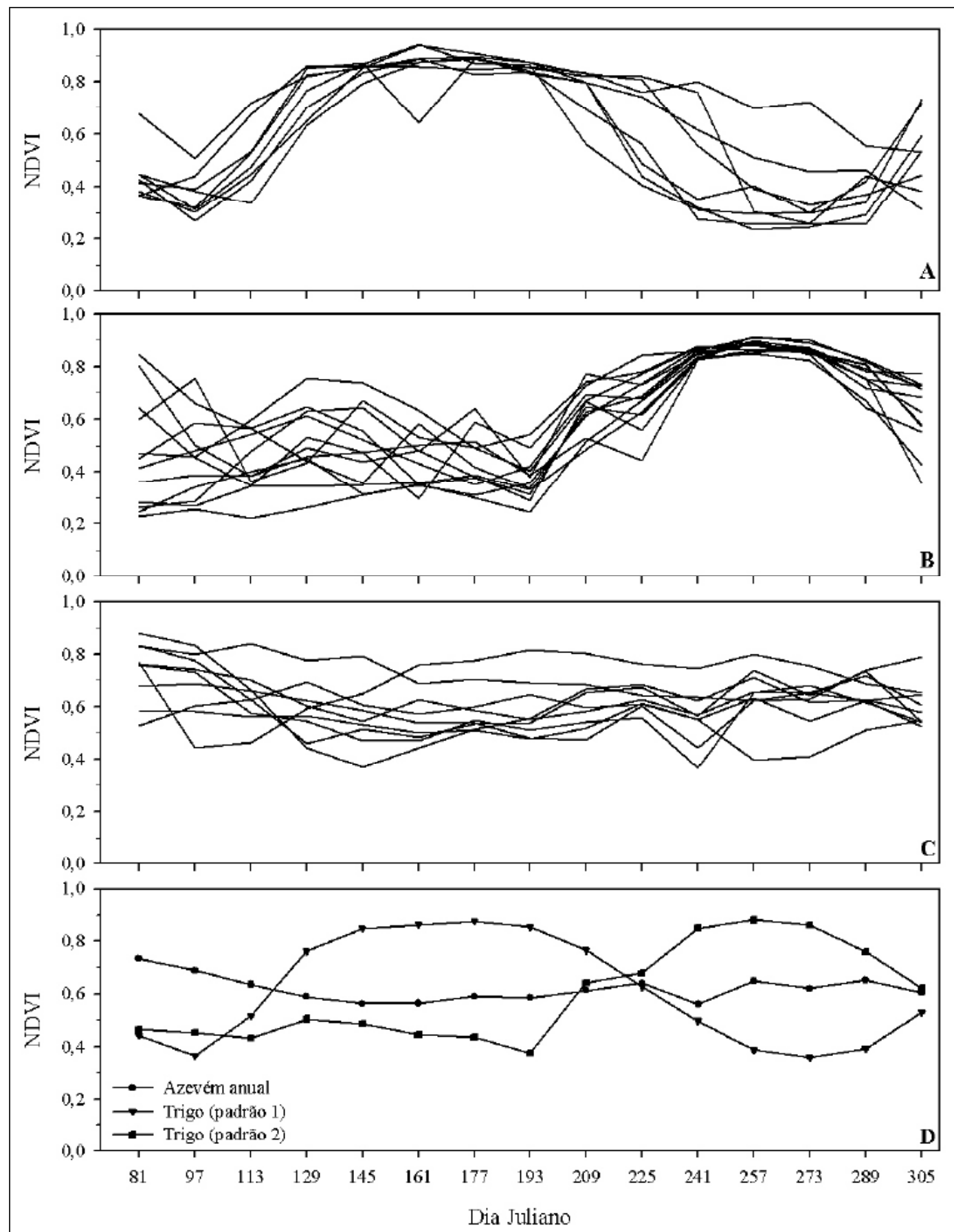

Figura 2 - Variação temporal dos valores de NDVI: (A) trigo, padrão 1; (B) trigo, padrão 2; (C) azevém anual; e (D) médias das observações para os dois padrões de trigo e para o azevém anual. 
Nas áreas cultivadas com azevém anual a variação da resposta espectral nas imagens de NDVI não evidenciou nenhum padrão característico quando se analisa o conjunto das curvas apresentadas na figura $2 \mathrm{C}$. Apenas com a análise dos valores médios de NDVI para o azevém anual (Figura 2D) é possivel o entendimento do padrão multitemporal da resposta espectral. Foram observados um padrão de diminição linear entre a segunda quinzena de março (dia 81) e a segunda quinzena de maio (dia 145) e uma estabilização dos valores médios de NDVI próximos a 0,6 até o final da estação de baixas temperaturas do ar, que na região sul corresponde ao final da primavera (dia 305). Esse padrão pode ser compreendido pela análise da relação entre a biomassa de folhas verdes e o período de cultivo do azevém anual, apresentado na figura 1B. Como esse cereal é utilizado para a produção de forragem, os animais iniciam o pastoreio após a emissão dos afilhos e, como as plantas são constantemente pastoreadas, elas não completam todas as etapas do ciclo fenológico, a partir da etapa de alongamento dos entrenós (BARBOSA et al., 2008). A diminuição dos valores de NDVI no início do cicloé associada ao início do pastoreio pelos animais, já que essa espécie é utilizada como suporte forrageiro no período em que a vegetação campestre natural do bioma Pampa para seu crescimento. Os valores de NDVI no início do ciclo do azevém anual mais altos que os observados para o trigo são explicados em função da maior densidade de sementes por área utilizada nas áreas destinadas ao pastoreio, visando uma maior produção de folhas verdes, que são consumidas diretamente pelos animais. A estabilização dos valores de NDVI está associada ao manejo das áreas que pode variar entre a supressão do pastoreio em períodos curtos, o que permite um acúmulo de biomassa aérea, ou a variação da carga animal em pastejo, o que permite que ocorram crescimentos e rebrotas da vegetação durante o pastoreio (IDO et al., 2005).

Enquanto se observa para o trigo a curva temporal padrão da vegetação, associada às diferentes etapas do ciclo fenológico, esse mesmo padrão não é observado para o azevém anual. Uma análise da figura 2D evidencia as diferenças que o pastoreio dos animais impõe ao dossel e consequentemente à resposta espectral multitemporal das espécies cultivadas com o propósito de produção de forragem. Dessa forma, verifica-se que as diferenças nos padrões de resposta espectral multitemporal dos cereais de estação fria cultivados com diferentes propósitos indicam a possibilidade de separação dessas áreas em imagens de satélite. Essa separação fica condicionada à utilização de imagens de mais de uma data, adquiridas em épocas que permitam a identificação das diferenças das respostas espectrais dos diferentes cultivos, à semelhança do trabalho realizado por HILL et al. (1999). A utilização dos padrões apresentados na figura 2D para o monitoramento das condições de cultivo fica condicionada a uma análise desses padrões em anos com diferentes condições climáticas, uma vez que o acúmulo de biomassa verde para o pastoreio e a produtividade de grãos são uma consequência direta dos efeitos do clima na fisiologia das plantas. Sabe-se que anos de ocorrência do fenômeno La Niña são favoráveis para o cultivo de trigo no Rio Grande do Sul, ao passo que anos da ocorrência do fenômeno El Niño são desfavoráveis para essa cultura. No caso específico da influência do fenômeno El Niño sobre o trigo, o excesso de precipitação pluvial coincide com o período de maturação e a colheita dos grãos, mas esse mesmo padrão de precipitação pluvial pode ser favorável ao acúmulo de biomassa de folhas no azevém anual, as quais, nessa espécie, são utilizadas para o pastoreio (BERLATO \& FONTANA, 2003).

\section{CONCLUSÃO}

A análise do padrão multitemporal das áreas cultivadas com espécies de mesma morfologia, como é o caso dos cereais de estação fria, mas com ciclo fenológico distinto em função do propósito do cultivo, como é o caso do trigo e do azevém anual, evidenciou padrões de resposta espectrais distintos. O trigo apresentou um padrão característico de um cultivo agrícola distinto do padrão apresentado pelo azevém anual.

Com base nas variações observadas entre os perfis temporais médios, entende-se que é possível a separação automática das áreas cultivadas com cereais de inverno, para a produção de grãos e pastagens. Para tanto devem ser utilizadas imagens adquiridas em épocas em que a separação espectral dessas áreas se evidencia, sendo o caso do início do ciclo do azevém anual e do máximo desenvolvimento do trigo.Recomenda-se uma análise de padrões espectrais para anos com diferentes padrões climáticos, definidos a partir da ocorrência dos fenômenos El Niño, La Niña e anos neutros, para que possam ser caracterizados os padrões espectrais para o trigo e o azevém anual de forma robusta, permitindo o monitoramento das condições de crescimento dos cultivos em modelos de estimativa de produtividade vegetal. 


\section{REFERÊNCIAS}

ASRAR, G. et al. Estimating absorbed photosynthetic radiation and leaf area index from spectral reflectance in wheat. Agronomy Journal, v.76, n.2, p.300-306, 1984.

BARBOSA, C.M.P. et al. Efeito de métodos e intensidades de pastejo sobre a ressemeadura natural de azevém anual. Acta Scientiarum. Animal Sciences, v.30, p.387-393, 2008. Disponível em: < http://periodicos.uem.br/ojs/index.php/ ActaSciAnimSci/article/view/6463/6463>. Acesso em: 20 ago. 2009. doi: 10.4025/actascianimsci.v30i4.6463.

BERlato, M.A.; FONTANA, D.C. El Niño e La Niña. Porto Alegre: UFRGS, 2003. 110p.

CAMPBELL, J.B. Introduction to remote sensing. New York: Taylor \& Francis, 2006. 625p.

DORAISWAMY, P.C. et al. Crop condition and yield simulations using Landsat and MODIS. Remote Sensing of Environment, v.92, p.548-559, 2004. Disponível em: <http:/ /dx.doi.org/10.1016/j.rse.2004.05.017>. Acesso em: 20 ago. 2009. doi:10.1016/j.rse.2004.05.017.

FISHER, J.I. et al. Green leaf phenology at Landsat resolution: Scaling from the field to the satellite. Remote Sensing of Environment, v100, p.265-279, 2006. Disponível em: <http://dx.doi.org/10.1016/j.rse.2005.10.022>. Acesso em: 20 ago. 2009. doi:10.1016/j.rse.2005.10.022.

HILL, M.J. et al. Pasture land cover in eastern Australia from NOAA-AVHRR NDVI and classified Landsat TM. Remote Sensing of Environment, v.67, p.32-50, 1999. Disponível em: <http://dx.doi.org/10.1016/S00344257\%2898\%2900075-3>. Acesso em: 20 ago. 2009. doi:10.1016/S0034-4257(98)00075-3.

IDO, O.T. et al. Pastagem de azevém associada com leguminosas de inverno sob diferentes níveis de oferta de forragem, na região Sul do Paraná. Scientia agraria, v.6, n.1-2, p.15-21, 2005.
JACKSON, R.D.; HUETE, A.R. Interpreting vegetation indices. Preventive Veterinary Medicine, v.11, p.185200, 1991.

JACKSON, R.D. et al. Discrimination of growth and water stress in wheat by various vegetation indices through clear and turbid atmospheres. Remote Sensing of Environment, v.13, n.3, p.187-208, 1983. Disponível em: <http:// dx.doi.org/10.1016/0034-4257\%2883\%2990039-1>. Acesso em: 20 ago. 2009. doi:10.1016/0034-4257(83)90039-1.

LILLESAND, T.M. et al. Remote sensing and image interpretation. Hoboken: John Wiley \& Sons, 2004. 763p.

PAX-LENNEY, M.; WOODCOCK, C.E. Monitoring agricultural lands in Egypt with multitemporal Landsat TM imagery: how many images are needed? Remote Sensing of Environment, v.59, p.522-529, 1997. Disponível em: <http:/ /dx.doi.org/10.1016/S0034-4257\%2896\%2900124-1>. Acesso em: 20 ago. 2009 doi:10.1016/S00344257(96)00124-1.

XIONG, X.; BARNES, W. MODIS calibration and characterization. In: QU, J.J. et al. Earth science satellite remote sensing: data, computational processing, and tools. Berlin: Springer, 2006. Cap.5, p.77-97.

UNGANAI, L.S.; KOGAN, F.N. Drought monitoring and corn yield estimation in southern Africa from AVHRR data. Remote Sensing of Environment, v.63, p.219-232, 1998. Disponível em: <http://dx.doi.org/10.1016/S00344257\%2897\%2900132-6>. Acesso em: 20 ago. 2009. doi:10.1016/S0034-4257(97)00132-6.

XIN, J. et al. Mapping crop key phenological stages in the North China Plain using NOAA time series images. International Journal of Applied Earth Observation and Geoinformation, v.4, p.109-117, 2002. Disponível em: <http://dx.doi.org/10.1016/S0303-2434\%2802\%29000077>. Acesso em: 20 ago. 2009. doi:10.1016/S03032434(02)00007-7. 